\title{
USO DA CROMATOGRAFIA GASOSA PARA AVALIAÇÃO DA DIFUSÃO EM MEMBRANA DE POLIETILENO DE ALTA DENSIDADE (PEAD) EM CONTATO COM HIDROCARBONETO
}

\author{
Use of gas chromatography for the evaluation of the diffusion in High Density PolyEthylene (HDPE) membrane in contact \\ with hydrocarbon
}

\author{
Clever Aparecido Valentin', Benedito de Souza Bueno ${ }^{2}$, Paulo César Lodi ${ }^{3}$ \\ ${ }^{1,2}$ Escola de Engenharia de São Carlos (EESC-USP), Departamento de Geotecnia \\ Avenida Trabalhador Sãocarlense, 400 CP. 359 São Carlos, SP \\ ${ }^{1}$ E-mail: cclever@sc.usp.br \\ ${ }^{2}$ E-mail: bsbueno@sc.usp.br \\ ${ }^{3}$ Universidade Estadual Paulista "Júlio de Mesquita Filho" (Unesp) \\ Faculdade de Engenharia de Bauru (FEB), Departamento de Engenharia Civil \\ Avenida Eng. Luiz Edmundo C. Coube, 14-01 Bairro Vargem Limpa, Bauru, SP \\ E-mail: plodi@feb.unesp.br
}

\begin{abstract}
RESUMO
Os constantes vazamentos de combustíveis derivados do petróleo nos postos de abastecimento têm gerado grande preocupação em diversos países do mundo. Tais combustíveis apresentam, em sua composição, compostos orgânicos, entre eles os hidrocarbonetos poliaromáticos (HPA) nocivos à saúde humana. Este trabalho avaliou o estudo da eficiência de uma camada de impermeabilização constituída por uma geomembrana de Polietileno de Alta Densidade (PEAD) de 2,5 mm de espessura. O estudo baseou-se em análises do processo difusivo na geomembrana intacta por meio de um permeâmetro desenvolvido para tal finalidade. A membrana foi colocada no meio do sistema para separar duas fases, a saber: solo local impregnado com óleo diesel em uma face e água pura na face oposta. A técnica de cromatografia foi utilizada para avaliar a contaminação na água pura. As análises foram realizadas mensalmente num período total de 6 meses de pesquisa. Os resultados mostraram que a membrana apresentou desempenho menos satisfatório para os compostos antraceno e naftaleno. Apesar disso, os resultados mostraram que a membrana de PEAD é uma boa alternativa para prevenção da contaminação da água e do solo pelos compostos estudados pelo período aproximado de um ano tendo-se em vista o desempenho no período estudado.

Palavras-chave: hidrocarbonetos, difusão, cromatografia gasosa.
\end{abstract}

\section{ABSTRACT}

The constant petrol fuel leak in gas stations has caused concern in many countries around the world. Those fuels have toxic organic compounds in their composition, like Polycyclic Aromatic Hydrocarbons (PAH), which are harmful to the human health. In this work the efficiency of the protection layer with a High Density Polyethylene (HDPE) membrane of $2.5 \mathrm{~mm}$ thickness was evaluated. The study was based in the diffusive process in the intact membrane by a permeameter developed to evaluate the diffusive process. The membrane was putted in the middle of the system to separate two sides: a local soil impregnated with diesel oil (in one side) and pure water (in the other side). The chromatography technique was conducted to evaluate the contamination in the pure water. The analyses were made monthly in a total period of 6 months of research. The results tests show that the membrane was less effective to antracene and naphthalene compounds. Despite that, the results showed that the HDPE membrane is a good alternative to prevent contamination of water and soil by the compounds under study up to one year, based on the performance in the time of study.

Keywords: hydrocarbons, diffusion; gas chromatography.

\section{1 - INTRODUÇÃO}

O armazenamento de combustíveis automotivos em tanques subterrâneos é considerado potencialmente poluidor no contexto mundial. A ocorrência de vazamentos no seu armazenamento pode comprometer a qualidade do solo, dos aquíferos subterrâneos e, consequentemente, afetar a saúde humana. Os constantes vazamentos de combustíveis derivados do petróleo nos postos de abastecimento têm gerado grande preocupação uma vez que estes combustíveis apresentam em sua composição compostos orgânicos, entre eles os hidrocarbonetos poliaromáticos (HPA) nocivos à saúde humana (VALENTIN, 2008).

Na década de 1980, a Agência Americana de Proteção Ambiental (EPA) estipulou um prazo de dez anos (19881998) para que os proprietários de Sistemas de Armazenamento Subterrâneo de Combustíveis (SASC) cumprissem as exigências técnicas de substituição de seus equipamentos e consequente implantação de medidas preventivas (EPA, 2004). No Brasil, o processo de licenciamento ambiental que visa à adequação das atividades de SASC passou a ser obrigatório a partir da Resolução CONAMA-273, de 29 de novembro de 2000. Esta resolução estabelece o cadastramento e o 
licenciamento ambiental de postos e sistemas retalhistas de combustíveis. A partir da Resolução SMA-5, de 28 de março de 2001, o Setor de Planejamento de Ações Especiais da CETESB fez o cadastramento ambiental de 8.489 postos e sistemas retalhistas de combustíveis no Estado de São Paulo - sendo 1.874 na Capital, 5.544 no Interior e 2.945 na Região Metropolitana, incluindo o Município de São Paulo - e criou uma agenda fixando o prazo de cinco anos para que os estabelecimentos em operação fossem licenciados (CETESB, 2005).

De acordo com o levantamento do Cadastro de Acidentes Ambientais - CADAC (CETESB, 2005), no período de 1984 a 2004 as situações emergenciais de vazamentos de combustíveis automotivos em postos e sistemas retalhistas de combustíveis no estado de São Paulo, corresponderam a aproximadamente 9\% (550) do total de casos registrados (5.884). Essas atividades comerciais também são responsáveis pelo elevado número de áreas contaminadas. Até novembro de 2004, a CETESB tinha registrado 1.336 áreas contaminadas. Desse total, $69 \%$ (931) foram causadas por vazamentos de postos de combustíveis.

Como fatores significativos que contribuem para o elevado número de ocorrências dessa natureza, incluem-se os envelhecimentos dos tanques, das tubulações e acessórios nos locais de armazenamento de combustível.

Os acidentes ambientais em postos e sistemas retalhistas de combustíveis, com destaque para o comércio varejista de combustíveis automotivos, caracterizam-se como uma importante fonte de contaminação do solo e de águas subterrâneas, principalmente nas regiões metropolitanas. O processo de contaminação pode ser de extrema gravidade, visto que estes ambientes apresentamse confinados como galerias subterrâneas de concessionárias públicas ou privadas, gerando riscos de incêndio e explosão (CETESB, 2005).

Outra séria consequência dessas ocorrências é o incômodo causado pelo odor de combustível quando este atinge $o$ interior de residências e estabelecimentos comerciais. Este processo expõe os seres humanos a substâncias tóxicas, entre as quais estão os hidrocarbonetos monoaromáticos, mais conhecidos como BTEX (benzeno, tolueno, etilbenzeno e xilenos) (BAIRD, 2002). Embora não seja muito comum é também possível ocorrer contaminação das redes de abastecimento de água potável por meio da migração de poluentes para o interior das tubulações (CETESB, 2003).

Presente nos combustíveis automotivos, gasolina e óleo diesel, os HPA fazem parte de uma importante classe de contaminantes dos solos e de águas subterrâneas, por trazerem grandes prejuízos à saúde humana.

Os tanques de combustíveis possuem impermeabilização com membranas de PEAD. No entanto, devido ao processo de degradação e por processos difusivos, pode ocorrer vazamento de combustível vindo a contaminar o solo e a o lençol freático. Neste sentido, considerando as informações sobre acidentes envolvendo tais substâncias, principalmente os vazamentos em tanques de armazenamento, estudos são fundamentais para a avaliação do processo de contaminação bem como para a prevenção de certas doenças buscando-se preservar a água de boa qualidade para as gerações futuras.

Dessa forma, esse trabalho apresenta uma técnica para a avaliação da eficiência de uma membrana de polietileno de alta densidade (PEAD) em contato com hidrocarbonetos mediante análise do processo difusivo por meio de cromatografia gasosa após um período de 6 meses.

\section{2 - PARTE EXPERIMENTAL}

As etapas de materiais e métodos utilizados estão descritas nas seções a seguir.

\subsection{Materiais}

Utilizou-se nesta pesquisa uma amostra de membrana de polietileno de alta densidade (PEAD) de 2,5 $\mathrm{mm}$ de espessura conforme a Figura 1. Esse material é de uso comum na impermeabilização de tanques de combustíveis.

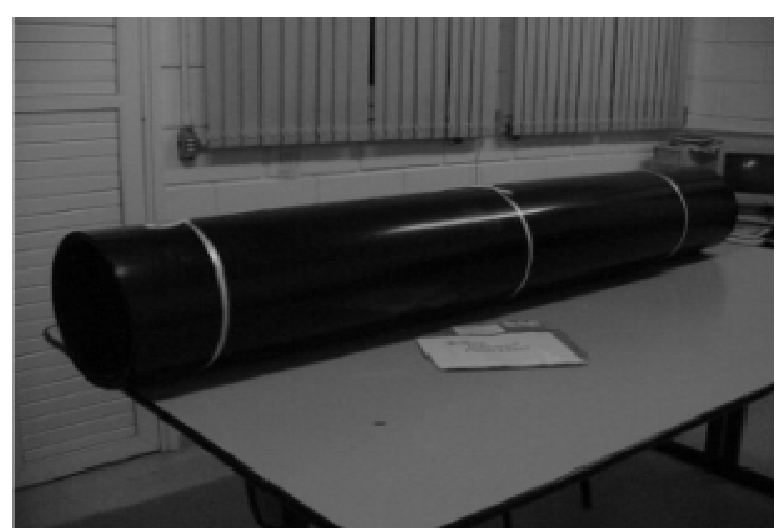

Figura 1 - Bobina a membrana de $\operatorname{PEAD}(2,5 \mathrm{~mm})$

\subsection{Métodos}

Foram realizados ensaios de difusão, de cromatografia gasosa e de recuperação das amostras.

\subsubsection{Ensaios de difusão}

Os ensaios de permeação, ou difusão dos compostos de estudo, foram realizados em um permeâmetro construído com a finalidade de simular um sistema de isolamento (impermeabilização), entre um ambiente contaminado (solo contaminado com óleo diesel) e outro sem contaminação (água pura), conforme a Figura 2. 


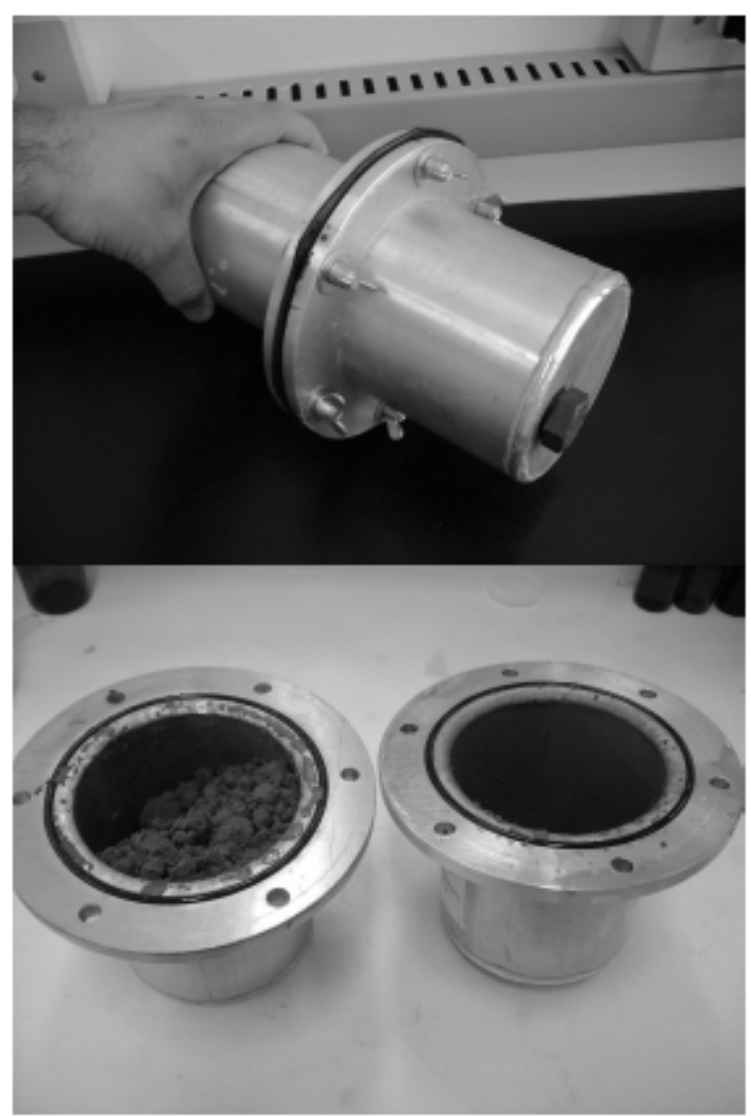

Figura 2 - Permeâmetro para isolamento

Uma das partes do permeâmetro é totalmente fechada enquanto que a outra possui uma abertura que permite a realização de coletas para análise. As duas partes são do mesmo tamanho com as seguintes dimensões: altura $(10,5$ $\mathrm{cm})$, diâmetro interno $(9,5 \mathrm{~cm})$, diâmetro externo $(15,8 \mathrm{~cm})$ e diâmetro do furo do parafuso $(1,5 \mathrm{~cm})$. Parafusos com porcas e arruelas foram utilizados para promover a junção entre as partes bem como anéis de borracha foram utilizados para a vedação entre as faces e a membrana. No centro do dispositivo posicionou-se a membrana de PEAD intacta. O sistema foi mantido na posição horizontal, garantindo o contato solo-membrana-água. Para a simulação de contaminação foram adicionados $140 \mathrm{~mL}$ de um óleo diesel comercial em $700 \mathrm{~g}$ de solo, de um lado do permeâmetro e, para a verificação de contaminação, foram adicionados $1000 \mathrm{~mL}$ de água mili-Q na outra parte com um orifício para as coletas. Essa dosagem foi obtida por meio de vários testes preliminares, donde se obteve a mais satisfatória para o preenchimento dos compartimentos. A concentração inicial testada variou de 100-600 g de solo. Os resultados foram todos similares. Ao longo de seis meses, foram realizadas seis coletas (uma a cada mês) de $10 \mathrm{~mL}$ de água para realizar o ensaio por Cromatografia Gasosa com detector de massas (GC-MS).

\subsubsection{Cromatografia gasosa}

Para a análise cromatográfica dos HPA utilizou-se um Cromatógrafo a Gás da marca Shimadzu e modelo GC
2010, acoplado a um Espectrômetro de Massas da mesma marca e modelo GCMS 2010 Plus, com auto sampler AOC 5000. A coluna utilizada foi do tipo RTx-5MS, $30 \mathrm{~m}$ de comprimento por $0,25 \mathrm{~mm}$ de diâmetro interno por 0,25 $\mu \mathrm{m}$ de espessura de filme.

Os analitos foram extraídos do solo contaminado, dos ensaios de recuperação e das amostras de água pela extração em fase sólida, em cartuchos da marca Varian. A água foi passada diretamente pelo cartucho e os analitos foram eluidos com $0,5 \mathrm{~mL}$ de metanol $+3 \mathrm{~mL}$ de acetato de etila $+3 \mathrm{~mL}$ de diclorometano, adicionados em frações de $1 \mathrm{~mL}$, sob fluxo de $1 \mathrm{~mL} / \mathrm{min}$. As condições cromatográficas utilizadas foram: temperatura inicial da coluna ambiente, rampa de $45{ }^{\circ} \mathrm{C} / \mathrm{min}$, depois $30{ }^{\circ} \mathrm{C} / \mathrm{min}$ até $130{ }^{\circ} \mathrm{C}$, depois $20^{\circ} \mathrm{C} / \mathrm{min}$ até $300^{\circ} \mathrm{C}$ por 10 minutos. $\mathrm{O}$ tempo total de ensaio foi de 23 minutos. A temperatura do injetor foi de $260{ }^{\circ} \mathrm{C}$ com divisor de fluxo de $12 \mathrm{~mL} / \mathrm{min}$, no modo de injeção com divisor de 10:1, com volume de injeção de $1 \mu \mathrm{L}$. Detector de massas com temperatura de linha de transferência de $280{ }^{\circ} \mathrm{C}$ e fonte de íons de $230{ }^{\circ} \mathrm{C}$, e modo de varredura completa de 60-300.

\subsubsection{Ensaios de recuperação}

Para os testes de recuperação foram dopadas duas amostras de água Mili-Q com os seguintes compostos (a uma concentração de 460 ppb): Naftaleno, Acenaftileno, Acenafteno, Fluoreno, Fenantreno, Antraceno, Fluoranteno, Pireno, Benzo(a)antraceno, Criseno, Benzo(k)fluoranteno, Benzo(a)pireno, Dibenzo(a,h)antraceno, Benzo(g,h,i)pirileno, Indeno(1,2,3cd)pireno e Benzo(b)fluoranteno.

\section{3 - RESULTADOS E DISCUSSÃO}

Para os ensaios de difusão dos contaminantes foram feitos, preliminarmente, os testes de recuperação para os seguintes HPA: Naftaleno, Acenaftileno, Acenafteno, Fluoreno, Fenantreno, Antraceno, Fluoranteno, Pireno, Benzo(a)antraceno, Criseno, Benzo(k)fluoranteno, Benzo(a)pireno, Dibenzo(a,h)antraceno, Benzo(g,h,i)pirileno, Indeno(1,2,3-cd)pireno e Benzo(b)fluoranteno.

A Tabela 1 apresenta as porcentagens de recuperação para cada um dos HPA estudados. A Tabela 2 apresenta de forma sintetizada, os compostos e as concentrações encontradas no solo contaminado com óleo diesel comercial. $O$ óleo diesel foi adicionado na fase do permeâmetro a uma concentração de $5000 \mathrm{~g} / \mathrm{L}$, (700 g de solo por $140 \mathrm{~mL}$ ) para o teste de difusão dos compostos através da membrana. Finalmente, foram realizados os testes em seis coletas de amostras de água da parte isenta de contaminantes do permeâmetro, para as análises qualitativas e quantitativas, de cada composto da Tabela 2 , em cada período de amostragem. Os cinco compostos foram identificados e quantificados, conforme ilustra a Tabela 3. 
Tabela 1 - Resultados dos testes de recuperação dos HPA

\begin{tabular}{lcccc}
\hline \multicolumn{1}{c}{ Compostos } & \% da $1^{\text {a }}$ Recuperação & \% da $2^{\text {a }}$ Recuperação & Desvio Padrão & $\begin{array}{c}\text { Coeficiente de } \\
\text { Variação (\%) }\end{array}$ \\
\hline Naftaleno & 98 & 106 & 5,657 & 5,546 \\
Acenaftileno & 96 & 104 & 5,657 & 5,657 \\
Acenafteno & 100 & 96 & 2,828 & 2,886 \\
Fluoreno & 101 & 105 & 2,828 & 2,746 \\
Fenantreno & 100 & 104 & 2,828 & 2,773 \\
Antraceno & 103 & 107 & 2,828 & 2,694 \\
Fluoranteno & 118 & 114 & 2,828 & 2,438 \\
Pireno & 115 & 105 & 7,071 & 6,428 \\
Benzo(a)antraceno & 125 & 133 & 5,657 & 4,385 \\
Criseno & 20 & 51 & 21,920 & 61,747 \\
Benzo(k)fluoranteno & 154 & 143 & 7,778 & 5,238 \\
Benzo(a)pireno & 125 & 97 & 19,799 & 17,837 \\
Dibenzo(a,h)antraceno & 25 & 109 & 59,397 & 88,652 \\
Benzo(g,h,i)pirileno & 35 & 44 & 6,364 & 16,111 \\
Indeno(1,2,3-d)pireno & 113 & 91 & 15,556 & 15,251 \\
Benzo(b)fluoranteno & 82 & 81 & 0,707 & 0,868 \\
\hline
\end{tabular}

Tabela 2 - Compostos e concentrações encontradas no solo contaminado

\begin{tabular}{ccccc}
\hline \multicolumn{5}{c}{ Concentrações $(\mathrm{mg} / \mathrm{kg})$} \\
\hline Naftaleno & Fluoreno & Antraceno & Pireno & Criseno \\
12,275 & 1,138 & 4,824 & 0,624 & 0,139 \\
\hline
\end{tabular}

Deve-se ressaltar que, pelo fato da quantidade de água retirada mensalmente ser muito pequena $(10 \mathrm{~mL})$, os valores mostrados na Tabela 3 foram corrigidos nos cálculos das concentrações. Esse fato é importante porque a diminuição do solvente (água) ao longo do tempo aumenta a concentração dos compostos. Dessa forma, os valores apresentados levaram em conta a variação do solvente.

Tabela 3 - Compostos e concentrações encontradas em cada período de análise

\begin{tabular}{ccccccc}
\hline \multicolumn{5}{c}{ Concentrações $(\mu \mathrm{g} / \mathrm{L})$} \\
\hline Compostos & 1 mês & 2 meses & 3 meses & 4 meses & 5 meses & 6 meses \\
Naftaleno & 61 & 62 & 90 & 102 & 173 & 164 \\
Fluoreno & 42 & 41 & 45 & 42 & 106 & 65 \\
Antraceno & 108 & 100 & 87 & 110 & 180 & 110 \\
Pireno & 22 & 38 & 18 & 20 & 22 & 19 \\
Criseno & 72 & 79 & 62 & 120 & 119 & 77 \\
\hline
\end{tabular}

A Figura 3 ilustra as curvas de porcentagem em função do tempo, para os cinco compostos. 


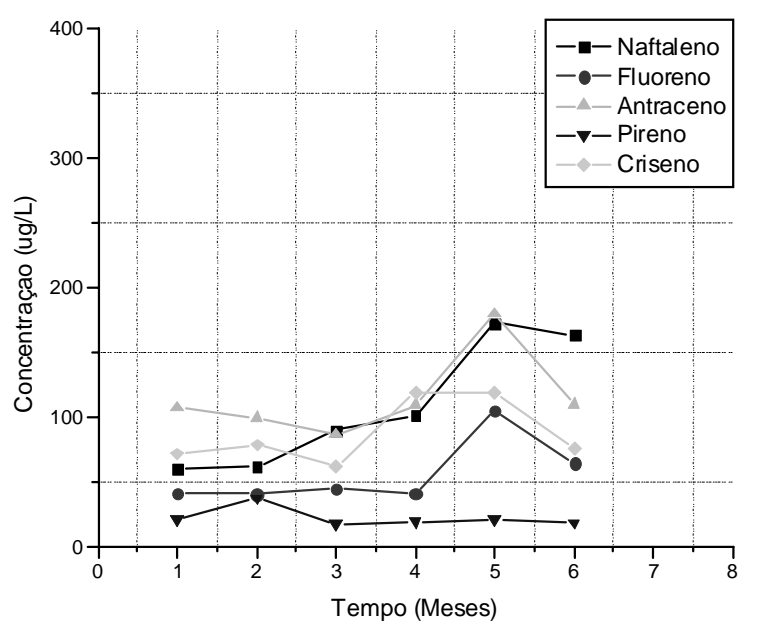

Figura 3 - Curvas da concentração de cada composto presente na água pela análise da difusão

A análise geral das curvas mostra que, excetuando-se o composto Pireno, os demais compostos tendem a permear mais pela membrana em função do tempo e que há uma boa eficiência de isolamento a esses compostos, tendo em vista a alta concentração na fase contaminada. Esse detalhe é importante tendo-se em vista que esses materiais são frequentemente usados para vedação de tanques de hidrocarbonetos, como em postos de abastecimentos. A técnica de cromatografia gasosa mostrou-se eficiente para detectar os compostos que difundiram pela membrana em função do tempo. Deve-se levar em conta que membranas de PEAD são permeoseletivas e, como mostram os resultados, tendem a permear mais certos compostos em detrimento de outros.

Os resultados mostram que a técnica como um todo (permeâmetro associado à cromatografia) pode ser utilizada para eventuais pesquisas de contaminação de hidrocarbonetos em contato com membranas de PEAD. Essa técnica mostrou-se interessante pelo baixo custo e pela facilidade de execução.

\section{4 - CONCLUSÕES}

A partir dos resultados obtidos conclui-se que o modelo de ensaio de difusão (permeâmetro) e a técnica de cromatografia gasosa adotados foram eficientes para realizar o processo difusivo e detectar as taxas de compostos policíclicos aromáticos que permearam pela geomembrana. Devido à sua permeoseletividade, a geomembrana utilizada apresentou maiores taxas de difusão (pior desempenho) para os compostos antraceno e naftaleno.

\section{REFERÊNCIAS BIBLIOGRÁFICAS}

BAIRD, C. Química ambiental. 2. ed., Bookman, Porto Alegre, 2002.

CETESB - Companhia Ambiental do Estado de São

Paulo. Relatórios de atendimento a acidentes ambientais em postos e sistemas retalhistas de combustíveis 1984 a
2004. São Paulo, 2005.

CETESB - Companhia Ambiental do Estado de São Paulo. Guia para avaliação do potencial de contaminação em imóveis. São Paulo, 2003.

EPA - Environmental Protection Agency. Test methods for polynuclear aromatic hydrocarbons 8310. Disponível em:

$<\mathrm{http} / /$ www.epa.gov/osw/hazard/testmethods/sw846/pdfs/ 8310.pdf $>$. Acesso em: 28 jul. 2008.

VALENTIN, C. A. Estudo da degradação de geomembrana de polietileno de alta densidade de 2,5 mm de espessura frente à gasolina, óleo diesel e álcool combustível. 2008. 148 f. Dissertação (Mestrado), Escola de Engenharia de São Carlos (EESC-USP), Brasil, 2008. 